\title{
Cerebrospinal fluid zinc concentrations in febrile convulsions
}

\author{
Ben Zion Garty, Rachel Olomucki, Tally Lerman-Sagie, Menachem Nitzan
}

\begin{abstract}
Zinc modulates the activity of glutamic acid decarboxylase, the rate limiting enzyme in the synthesis of gammaaminobutyric acid (GABA), which is a major inhibitory neurotransmitter. Low cerebrospinal fluid GABA values have been reported in association with several seizure disorders, including febrile convulsions. It is also known that fever and/or infections may cause a reduction in serum zinc concentrations. In this study the hypothesis that febrile convulsions are related to low cerebrospinal fluid zinc was tested.

Cerebrospinal fluid zinc concentrations were measured in 66 febrile children: 32 with febrile convulsions, 18 with fever but without convulsions, and 16 with aseptic (viral) meningitis. There was no statistically significant difference in the cerebrospinal fluid zinc between the three groups of children, and the mean concentration was $26 \cdot 2 \mu \mathrm{g} /$. No significant relationship was found between either age, gender, maximal temperature, type of infection, or time of performance of the lumbar puncture and cerebrospinal fluid zinc concentration. These results do not support the hypothesis that febrile convulsions are related to reduced cerebrospinal fluid zinc concentrations.
\end{abstract}

(Arch Dis Child 1995; 73: 338-341)

Keywords: zinc, cerebrospinal fluid, convulsions.

Zinc is the most abundant trace metal in the human body and is essential for the normal development of the central nervous system. Zinc deficiency during pregnancy has been associated with a wide variety of congenital central nervous system anomalies in laboratory animals, ${ }^{1}$ and with neural tube defects and anencephaly in humans. ${ }^{2}$ The highest concentrations of zinc in the brain are found in the hippocampus (approximately $30 \mu \mathrm{g} / \mathrm{g}$ dry weight). ${ }^{3}$

Gamma-aminobutyric acid (GABA), a major inhibitory neurotransmitter, is produced by decarboxylation of L-glutamate. Glutamic acid decarboxylase is the rate limiting enzyme of GABA synthesis and requires pyridoxal phosphate or vitamin B6 for its activity. ${ }^{4}$ Zinc stimulates the activity of pyridoxal kinase, the enzyme that forms pyridoxal phosphate from pyridoxal, ${ }^{4}$ and thereby modulates the activity of glutamic acid decarboxylase and the synthesis of GABA. ${ }^{5}$

The GABA concentration in cerebrospinal fluid seems to be inversely related to seizure excitability. ${ }^{6}$ Low cerebrospinal fluid GABA values have been demonstrated in patients with intractable seizures. ${ }^{78}$ Administration of pyridoxine facilitates GABA formation and stops seizures in pyridoxine deficient syndromes. Picrotoxin has been found to cause seizures by blocking the GABA receptors. ${ }^{9}$ Furthermore, substances that increase the concentration of GABA in the brain are used as antiepileptic medications. Phenytoin and phenobarbitone facilitate discharge from GABA-containing neurones. ${ }^{1011}$ The antiepileptic activity of valproic acid is considered to be related to its ability to increase glutamic acid decarboxylase activity in the brain or to reduce the breakdown of GABA. ${ }^{12}$

Low zinc concentrations have been found in the serum and cerebrospinal fluid of people with epilepsy. ${ }^{1314}$ Low brain zinc concentrations were also reported in association with hepatic encephalopathy ${ }^{14}$ and in babies with a benign seizure disorder that appears around the fifth day of life. ${ }^{15}$

Febrile convulsions are seizures that occur in children between the age of 3 months to 6 years who are suffering from a febrile disease that does not directly involve the brain or the meninges and who have no previous history of non-febrile seizures. They affect $2-5 \%$ of children in this age group and account for approximately $30 \%$ of all seizure disorders in children. ${ }^{16}$ The pathogenesis of febrile convulsions is unknown. Several theories regarding possible metabolic changes during the rising phase of body temperature have been proposed, such as electrolyte disturbances or relative vitamin B6 deficiency, but do not explain the majority of cases. ${ }^{17}$ Conflicting data regarding cerebrospinal fluid GABA concentrations in patients with febrile convulsions have been reported: low cerebrospinal fluid GABA values was found in one study ${ }^{18}$ but were not confirmed in a second study. ${ }^{19} \mathrm{~A}$ third group postulated that fever causes seizures by reducing GABA concentration in the brain and cerebrospinal fluid in complex febrile convulsions. ${ }^{20}$

Several studies showed that infections and/or fever may cause a temporary reduction in serum zinc concentration. ${ }^{21} 22$ It was assumed that this is due to the action of interleukin-1, which is also a major inducer of fever. ${ }^{21}$ It was postulated that a reduction in the cerebrospinal fluid zinc concentration by fever might, in turn, be the cause of febrile convulsions. ${ }^{23}$ This hypothesis has not yet been tested. Therefore, we performed a prospective study of zinc concentrations in the cerebrospinal fluid of children with febrile convulsions. 
Clinical characteristics and cerebrospinal fluid (CSF) zinc concentrations of the patients

\begin{tabular}{|c|c|c|c|c|c|c|c|c|}
\hline \multirow[b]{2}{*}{ Diagnosis } & \multirow[b]{2}{*}{ No } & \multirow{2}{*}{$\begin{array}{l}M / F \\
(\%)\end{array}$} & \multirow{2}{*}{$\begin{array}{l}\text { Mean } \\
\text { age } \\
\text { (months) }\end{array}$} & \multirow{2}{*}{$\begin{array}{l}\text { Mean peak } \\
\text { temperature } \\
\left({ }^{\circ} \mathrm{C}\right)\end{array}$} & \multirow{2}{*}{$\begin{array}{l}\text { Mean peak } \\
\text { white cell } \\
\text { count } \\
\left(\times 10^{6} n\right)\end{array}$} & \multicolumn{2}{|c|}{$\operatorname{CSF} \operatorname{zinc}(\mu g /)$} & \multirow{2}{*}{$\begin{array}{l}95 \% \text { CI for } \\
\text { difference from } \\
\text { patient with } \\
\text { febrile convulsions }\end{array}$} \\
\hline & & & & & & Mean (SE) & Median & \\
\hline $\begin{array}{l}\text { Febrile convulsions } \\
\text { Fever } \\
\text { Aseptic meningitis }\end{array}$ & $\begin{array}{l}32 \\
18 \\
16\end{array}$ & $\begin{array}{l}60 / 40 \\
67 / 33 \\
75 / 25\end{array}$ & $\begin{array}{l}14 \\
28 \\
60\end{array}$ & $\begin{array}{l}39 \cdot 5 \\
39 \cdot 0 \\
38 \cdot 5\end{array}$ & $\begin{array}{l}15 \cdot 9 \\
13 \cdot 5 \\
11 \cdot 1\end{array}$ & $\begin{array}{l}26 \cdot 4(3 \cdot 0) \\
24 \cdot 6(1 \cdot 7) \\
27 \cdot 8(2 \cdot 7)\end{array}$ & $\begin{array}{l}21 \\
22 \\
24\end{array}$ & $\begin{array}{c}(-\overline{9} \cdot 2 \text { to } 6 \cdot 0) \\
(-13 \cdot 1 \text { to } 4 \cdot 7)\end{array}$ \\
\hline Total & 66 & $65 / 35$ & 29 & $39 \cdot 1$ & $14 \cdot 1$ & $26 \cdot 2(1 \cdot 7)$ & 22 & - \\
\hline
\end{tabular}

$\mathrm{CI}=$ confidence interval; $\mathrm{M}=$ male, $\mathrm{F}=$ female.

\section{Patients and methods}

The study included 66 children who were admitted to the department of paediatrics. Forty three were boys and 23 girls; ages ranged from 3 months to 11 years (mean 29 months). All underwent lumbar puncture as an emergency diagnostic procedure to exclude meningitis. Cerebrospinal fluid samples were collected directly into sterile, metal free plastic tubes which were sealed and stored at $-20^{\circ} \mathrm{C}$ until zinc measurement. Bloody cerebrospinal fluid samples were excluded from the study. The children were divided into three groups. Group 1 included 32 children who had febrile convulsions, with normal cerebrospinal fluid (white and red cells, protein, glucose) and negative cerebrospinal fluid cultures. Group 2 included 18 children who underwent a lumbar puncture because of fever without convulsions and whose cerebrospinal fluid was normal. Group 3 included 16 children with fever in whom cerebrospinal fluid analysis showed evidence of aseptic meningitis (white cell count in the range of $10-100 \times 10^{6} /$, protein up to $1 \mathrm{~g} / \mathrm{l}$, and negative cultures). Children with bacterial meningitis were excluded from the study.

All the children had a normal neurological history and none had received medications other than paracetamol or antibiotics. Most of the children in the febrile convulsion group had simple convulsions. No attempt was made to follow up the children who were tested for possible recurrent febrile seizures or the development of seizure disorders.

Respiratory system infection and/or otitis media was the cause of fever in 35 children $(70 \%)$ in the first two groups. Eight children $(12 \%)$ had a gastrointestinal tract infection. In the remaining seven children other causes of fever were found, such as periorbital cellulitis and exanthem subitum. Additional features of the patients are presented in the table.

The lumbar puncture was performed within three hours of the seizure in 25 children of the febrile convulsion group, and within 4-18 hours in the other seven children.

Zinc determination in the cerebrospinal fluid samples was performed by atomic absorption spectrophotometry. The cerebrospinal fluid samples were diluted 20-fold with water. Each sample was read twice and the average value calculated.

\section{STATISTICAL METHODS}

One way analysis of variance was performed on the reciprocal cerebrospinal fluid zinc concentration. The $95 \%$ confidence region was calculated on the reciprocal scale and inverted back to the original scale to yield joint 95\% confidence intervals for pairwise comparison.

\section{Results}

The mean cerebrospinal fluid zinc concentration of the 66 children tested was $26 \cdot 2 \mu \mathrm{g} / \mathrm{l}$. This value is similar to those reported in other studies. 2425

The average cerebrospinal fluid zinc concentration in the children with febrile convulsions was $26.4 \mu \mathrm{g} / \mathrm{l}$, in the children with fever but without convulsions $24.6 \mu \mathrm{g} / \mathrm{l}$, and in the aseptic meningitis group $27 \cdot 8 \mu \mathrm{g} / \mathrm{l}$ (table, figure). The differences were not statistically significant $(p<0 \cdot 418)$. The mean cerebrospinal fluid zinc concentration in the girls was lower than that in the boys, but this difference, too, was not significant. In addition, no significant differences in cerebrospinal fluid zinc concentration were found when measures such as age, type of infection, maximal temperature, peripheral white cell count, or timing of the lumbar puncture in relation to the seizure were compared (data not shown).

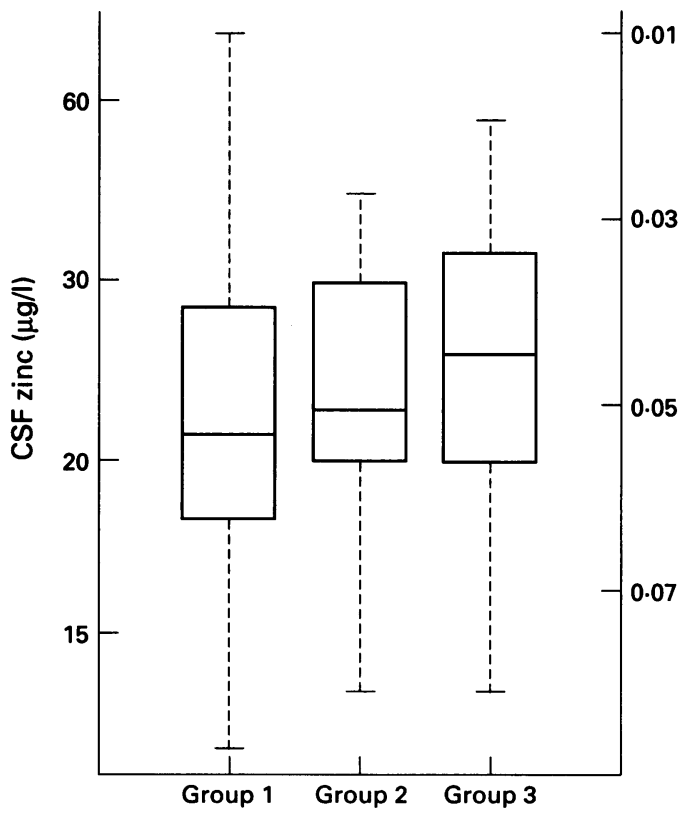

Boxplots of cerebrospinal fluid (CSF) zinc concentration for the three groups: group 1 patients with febrile convulsions; group 2 patients with fever; and group 3 patients with aseptic meningitis. The plot is done on the reciprocal scale (on the right); the original value scale is given on the left for ease of interpretation. The distribution of the data: the upper side of the box is at the upper quartile and the lower side of the box is at the lower quartile; the line in the centre is the value of the median of the group; the 'whiskers' extend to the maximum and minimum values. 


\section{Discussions}

Several theories have been proposed concerning the possible relationship between zinc, GABA, and convulsions. Zinc modulates the activity of glutamic acid decarboxylase, the rate limiting enzyme in the synthesis of GABA. ${ }^{4}$ In addition, zinc modulates the affinity of neurotransmitters, such as glutamate, to their receptors and facilitates the inhibitory effect of calcium on $N$-methyl-Daspartate receptors. ${ }^{26}$ Blocking glutamate receptors by kainic acid causes convulsions in laboratory animals; this effect may be prevented by zinc administration. ${ }^{27}$ As free zinc ions are toxic to numerous sulfydrylcontaining enzymes, including glutamic acid decarboxylase, and intraventricular administration of zinc was found to cause seizures, which were blocked by GABA, ${ }^{42}$ it was postulated that zinc binding proteins exist in the brain and control the concentrations of free zinc within relatively narrow concentrations. ${ }^{4}$

Fever is a known precipitating factor of seizures. In chicks homozygous for an epilepsy gene, an increase in body temperature evoked febrile seizures. Increasing brain GABA concentrations by administration of gammavinyl-GABA (GABA transaminase inhibitor) reduced the incidence of seizures in these birds. ${ }^{29}$

Low cerebrospinal fluid GABA values were reported in two studies of adults with seizure disorders. ${ }^{6} 7$ Low GABA in cerebrospinal fluid was found in 23 children with febrile convulsions compared with 16 seizure free children. ${ }^{18}$ This reduction in cerebrospinal fluid GABA was not reflected in plasma GABA concentrations. However, these findings were not confirmed in another study which compared children with simple febrile convulsions, children with a first afebrile convulsion, and a control group of febrile children. ${ }^{19}$ However, a correlation between the cerebrospinal fluid GABA values and age was found. In our study too, the cerebrospinal fluid zinc concentration in the older children (with aseptic meningitis) was higher than in the younger group, but this difference was not significant.

In a third study, the cerebrospinal fluid GABA concentrations in children with a simple febrile convulsion was not significantly different from that in the control group; however, when the seizures were complex and of more than 15 minutes' duration, cerebrospinal fluid GABA was reduced. ${ }^{20}$ An inverse relationship between body temperature and cerebrospinal fluid GABA values was also found. It was claimed that this finding may explain the occurrence of seizures in this age group. ${ }^{20}$

The cerebrospinal fluid zinc concentration in 32 children with febrile convulsions in our study was not significantly different from cerebrospinal fluid zinc values in other children with fever without seizures or with aseptic meningitis. There was no correlation between febrile convulsions, body temperature, or age and cerebrospinal fluid zinc values. These results do not support the assumption that febrile convulsions are related to reduced zinc in the central nervous system. However, this theory cannot be ruled out completely by our study because of the following limitations:

(A) The estimated time from the occurrence of the seizure to the performance of the lumbar puncture was up to three hours in the majority of our patients. It is possible that changes in zinc are transient and rapid, and the test performed too late.

(B) All children received antipyretic medication as soon as possible after arrival in the emergency room, and some of them even before arrival. It is possible that normalisation of the temperature restored cerebrospinal fluid zinc values before lumbar puncture was performed.

(C) Changes in zinc in the central nervous system might be a local event in certain brain areas which is not necessarily reflected by zinc cerebrospinal fluid measurements.

1 Hurley LS, Schraber RE. Congenital malformations of the nervous system in zinc deficient rats. In: Pfeiffer CC, ed. The international review of neurology. New York: Academic Press, 1972: 7.

2 Cavdar RO, Arcasoy A, Bayco T, Himmetoglu O. Zinc deficiency and anencephaly in Turkey. Teratology 1980; 22: 141.

3 Pfeiffer CC, Braverman ER. Zinc, the brain, and behavior. Biol Psychiatry 1982; 17: 531-2.

4 Ebadi M, Wilt S, Ramaley $R$, et al. The role of zinc and zinc-binding proteins in regulation of glutamic acid decarboxylase in brain. Chemical and biological aspects of vitamin B6. Catalysis. New York: Alan R Liss, 1984 (part A): 255-75.

5 Itoh $\mathbf{M}$, Ebadi $\mathbf{M}$. The selective inhibition of hippocampa glutamic acid decarboxylase in zinc-induced epileptic seizures. Neurochem Res 1982; 7: 1287-98.

6 Loscher W. Relation between GABA concentration in cerebrospinal fluid and seizure excitability. F Neurochem 1982; 38: 293-5.

7 Manyam NV, Katz L, Hare TA, et al. Levels of gammaaminobutyric acid in cerebrospinal fluid in various neurological disorders. Arch Neurol 1980; 37: 352-5.

8 Wood HJ, Hare TA, Glaeser BJ, et al. Low cerebrospinal fluid $\mathrm{Hamma-aminobutyric}$ acid content in seizure patients. Neurology 1979; 29: 1203-8.

9 Meldrum BS. Epilepsy and GABA mediated inhibition. Int Rev Neurobiol 1975; 17 : 1-36.

10 Julien RM, Halpern LM. Effects of diphenylhyphantoin and other antiepileptic drugs on epileptiform activity and Purkinje cell discharge rates. Epilepsia 1972; 13: 387-400.

11 McDonald RL, Barker JL. Phenobarbitol enhancer GABA mediated postsynaptic inhibition in cultured mammalian neurons. Transactions of the American Neurological Association 1977; 102: 139-40.

12 Woodbury DM, Kemp JW, Chow SY. Mechanisms of action of antiepileptic drugs. In: Ward AA, Penry JK, Purpura D, eds. Epilepsy. New York: Raven Press, 1983. 179-223.

13 Barbeau A, Donaldson J. Zinc, taurine and epilepsy. Arch Neurol 1974; 30: 52-8.

14 Palm R, Hallmans G. Zinc and copper metabolism in phenytoin therapy. Epilepsia 1982; 23: 453-61.

15 Goldber HJ, Sheehy EM Fifth day fits: an acute zinc deficiency syndrome? Arch Dis Child 1982; 57: 632-5.

16 Vymutt JG. Febrile seizures - current concepts. Clin Pediatr (Phila) 1980; 19: 731-8.

17 Lennox-Buchthal MA. Febrile convulsions - a reappraisal. Amsterdam: Elsevier Science Publishers, 1973: 15-6, 64-75.

8 Loscher W, Rating D, Siemes H. GABA concentration in cerebrospinal fluid of children with febrile convulsions. Epilepsia 1981; 22: 697-702.

19 Knight M, Ebert J, Parish RA, et al. Gamma aminobutyric acid in CSF of children with febrile seizures. Arch Neurol 1985; 42: 474-5.

20 Schmiegelow K, Johnsen AH, Ebbesen F, et al. Gammaaminobutyric acid concentration in lumber cerebrospinal fluid from patients with febrile convulsions and controls. Acta Paediatr Scand 1990; 79: 1092-8.

21 Beisel WR. Trace elements in infectious processes. Med Clin North Am 1976; 60: 831-49.

22 Hesse HV, Ryder CS, Beatty DW, et al. Serum zinc and copper levels in children with meningococcal disease. Eur f Pediatr 1985; 144: 152-6.

23 Izumi Y, Ishii K, Akiba K, Hayashi T. Hypozincemia during fever may trigger febrile convulsions. Med during fever may trigger

24 Potkin SG, Shore D, Fuller-Torrey E, et al. Cerebrospinal fluid zinc concentration in ex-heroin addicts and patients 
with schizophrenia: some preliminary observations. Biol Psychiatry 1982; 17: 1315-22.

25 Kapaki E, Segditsa J, Papageorgiou C. Zinc, copper and magnesium concentration in serum and CSF of patients magnesium concentration in serum and CSF of patients 373-8.

26 Peters C, Koh J, Choi DW. Zinc selectively blocks the action of $\mathrm{N}$-methyl-D-aspartate on cortical neurones. Science 1987; 236: 589-93.
27 Girgis S. Kindling as a model for limbic epilepsy. Neuroscience 1981; 6: 1695-706.

28 Pei Y, Zhao D, Huang J, Cao L. Zinc-induced seizures: a new experimental model of epilepsy. Epilepsia 1983; 24: 169-86.

29 Johnson DD, Wilcox $R$, Tuchek JM, Crawford RP. Experimental febrile convulsions in epileptic chickens. The anticonvulsant effect of elevated gamma-aminobutyric acid concentrations. Epilepsia 1985; 26: 466-71.

\section{Cholesterol and diet}

As everybody knows, too much cholesterol is bad for you and makes you die of coronary heart disease. Or, at least, low density lipoprotein cholesterol (LDL-C) is: high density lipoprotein cholesterol (HDL-C) is said to be antiatherogenic. The lesions of atherosclerosis begin in childhood and so, therefore, should attempts to prevent them. Whether population screening of young people for high serum cholesterol concentrations is likely to increase the general wellbeing is subject to debate but those at high risk because of family history might benefit from being checked. Children with very high cholesterol concentrations may need drug treatment but how should those found to have a modest increase in serum cholesterol be managed? Diet is the obvious answer but concerns have been expressed that cholesterol lowering diets for children might inhibit growth, lead to nutritional inadequacy, and be associated with psychosocial problems.

An important report in $\mathcal{F} A M A$ (The Writing Group for the DISC Collaborative Research Group, $\mathcal{F} A M A$ 1995; 273: 1429-35) testifies to the safety of dietary intervention.

Screening of 44000 children aged 8 to 10 years produced a study group of 663 with serum LDL-C concentrations between the 80th and 97th centiles for age and sex. These 663 children were randomly allocated to a dietary intervention group or a 'usual care' group. The first group were given intensive counselling and followed up regularly to promote a diet which provided $28 \%$ of energy from fat, less than $8 \%$ from saturated fat, up to $9 \%$ from polyunsaturated fat, and a daily cholesterol intake of less than $75 \mathrm{mg} / 1000 \mathrm{kcal}(4200 \mathrm{~kJ})$ to a maximum of $150 \mathrm{mg}$. The control group were told about the high serum cholesterol and provided with leaflets about 'heart-healthy eating'.

After three years mean concentrations of LDL-C fell from 3.38 to $2.98 \mathrm{mmol} / 1$ in the intervention group and from 3.38 to $3.07 \mathrm{mmol} / \mathrm{l}$ in the control group. The difference between the two groups was significant $(p=0.02)$. There was no evidence that the diet influenced growth, sexual maturation, nutrition, or psychosocial function.

The relatively small effects seen in the study might be due to non-compliance in some of the intervention group and dietary change in some of the control group.

This study has shown that dietary intervention aggressively pursued is capable of lowering serum LDL-C concentrations in children without apparent harm. What the effect on the incidence of atherosclerosis might be is unknown. 